\title{
Feedback on Teaching and Assessment Methodologies, being practiced in Islam Dental College - cross sectional study
} \author{
MIRZA ABDUL RAÜF 6 \\ ${ }^{1}$ Associate Professor and Head Department of Prosthodontics. Islam Dental College, Sialkot. \\ ${ }^{2}$ Associate Professor and Head Dental Materials, Avicenna Dental College, Lahore. \\ ${ }^{3}$ Senior Registrar, Dental Materials, Avicenna Dental College, Lahore. \\ ${ }^{4}$ Professor and Head Department of Prosthodontics, Avicenna Dental College, Lahore. \\ ${ }^{5}$ Assistant Professor, Oral Medicine, Islam Dental College, Sialkot \\ ${ }^{6}$ Professor and Head Department of OMFS, Islam Dental College, Sialkot. \\ Correspondence to Dr. Naveed Inayat, Email: naveedinayat092@gmail.com, cell 03334436164
}

NAVEED INAYAT ${ }^{1}$, NADIA MUNIR ${ }^{2}$, MEHVISH SAJJAD $^{3}$, MUHAMMAD USMAN MUNEER $^{4}$, MUHAMMAD MUDDASSAR $^{5}$,

\begin{abstract}
Background: The students are in the best position to judge the effectiveness of any teaching system. They may comment logically to assess the teaching and evaluation methods.

Aim: To analyze the student's feedback on teaching methodologies and effectiveness of methods being practiced in department of Prosthodontics in Islam Dental College Sialkot.

Methods: The cross sectional study was conducted in Islam Dental College Sialkot with a specially designed questionnaire. The study subjects were 100 students, 50 each from $3^{\text {rd }}$ year and final year BDS. The questionnaire was based on methods of teaching and assessments, in terms of content, time and relevance.

Results: Majority (85\%) agreed on the reliability of multimedia and digital methods of teaching .A huge number $(73 \%)$ were also satisfied with delivery and content of the lectures.80\% students were satisfied with teaching in lecture halls. $30 \%$ and $40 \%$ were not satisfied with teaching in clinics and OPDs respectively. Multiple Choice questions were the most favored type of assessment methods with $45 \%$ agreement.

Conclusion: Students were satisfaction with the teaching methods being practice in Islam dental College. MCQs were considered preferred assessment tools. There is a dire need to innovate Clinical and OPD Teaching regime in the dental colleges. As the lapse has a significant impact on knowledge and skill of the students.
\end{abstract}

Keywords: Blended Learning, Assessment tools, Feedback, teaching methods

\section{INTRODUCTION}

Medical education curriculum and standards have been raised globally over the last few years. To achieve the intended goal, modifications have been consistently being made in teaching and assessment methodologies in Pakistan ${ }^{1}$.

Teaching intended to be inclusive of mistakes. Feedback is one of the integral components of learning and teaching practice that produce positive impact on students' behaviour ${ }^{2}$.

Feedback is a two way process i.e. giving and receiving. Constructive feedbacks always enhance learning outcomes $^{3}$. In advanced countries it is a common practice to evaluate teaching through circulating structured questionnaires among learners ${ }^{4}$. Feedback is to improve skills and determine strength and weakness of ongoing learning process ${ }^{5}$.

Following the recent trends, teacher oriented methods like lectures, presentations \& demonstrations have been practiced. On the other hand, these methods are partially, in line with student oriented teaching regime. This includes tutorials, small group discussions and focused Group discussions. The provision of digital access or computer based learning enhances the effectiveness of face to face teaching. The goal is to combine the best compromises between different teaching modalities to provide better understanding 6 . Overall, this whole scenario falls under the

Received on 27-12-2020

Accepted on 14-04-2021 category of blended Learning. The aims of blended learning involve multiple delivery modalities. Multidimensional approach improves the learning experience and re enforcement of the content ${ }^{6}$. It is a blend of conventional methods and digital access based method including webinar and Audiovisual aids ${ }^{7}$. It is documented that Integrated mode of teaching greatly enhance and improve the cognitive and psychomotor skill of learner. The goal is to combine the best compromises between different teaching modalities to provide better understanding.

\section{MATERIAL AND METHOD}

This descriptive, cross-sectional study, at Islam Dental College, Sialkot was conducted, using nonprobability convenience sampling. The study was conducted from October $20^{\text {th }}$ to October $26^{\text {th }}, 2020$ in the department of Prosthodontics.

Research tool was a specially-designed, custom made; close-ended, questionnaire consisting of questions either in yes/no format or in multiple responses format. The questionnaire was a modified form of questionnaire used by Rafique et $\mathrm{al}^{1}$. It was developed on the basis of interviews and discussions with Dental students and faculty. There were questions about teaching methods and assessment tools. The study population included undergraduate students from third year and final year BDS. The students were requested to mention their agreement or disagreement, about the given statements in the feedback form. The respondents were asked, not to disclose their 
names, when answering the questions. The purpose was, to maintain the privacy and anonymity.

However, they were requested to write their age and gender on the proforma. The estimated sample size was $n=100$. The Students were approached during morning class lectures and clinical rotations on different days of the same week. They were briefed in the class lectures about the objectives of the study and were requested to answer the questions in 15 minutes. The questionnaires were collected at the end of the given time. Suggestions were also sought from the students for improving teaching and assessment methods.

Statistical analysis: Data was entered and analyzed using SPSS version 19. The standard deviation and means, for the age of the respondents, were calculated using Descriptive analysis. Frequencies and percentages were calculated for qualitative variables. Potential confounders like age and gender, were controlled by stratified tables.

\section{RESULTS}

The questionnaire was handed over to 50 students of Third year and 50 students of, final year BDS. The response rate was $100 \%$. The number of male and female respondents was 32:68 with the age ranged from 21 to 24 years.

Table 1: Demographic data $(n=100)$

\begin{tabular}{|l|l|l|}
\hline Gender & $\mathbf{n}$ & Mean age \\
\hline Male & $32(32 \%)$ & \\
\cline { 1 - 2 } Female & $68(68 \%)$ & $22.39 \pm 1.47$ \\
\hline
\end{tabular}

Students' response was obtained to various aspects of lectures delivered to large groups, including pace, content, explanations given, relevance of the displayed material and the language used. Overall, 73(73\%) students were satisfied with all aspects of lectures (Figure-1).

Figure-1: Students' Response regarding various aspects of lectures being delivered.

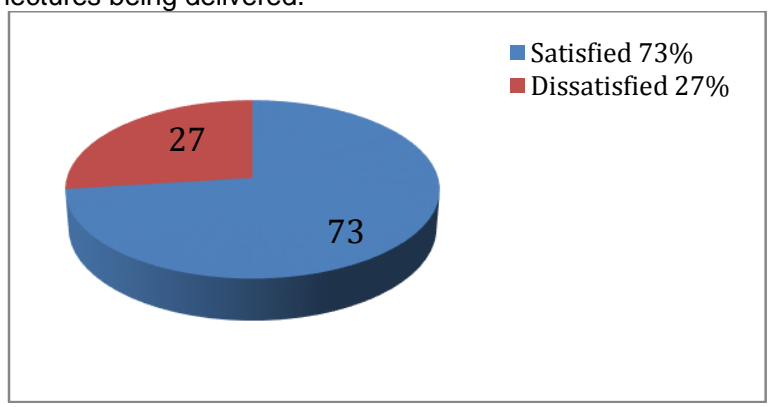

Majority of the students; $100(85 \%)$ students favoured multimedia power point presentations; (43 out of 85 students; $50.5 \%$ ); and audio-visual aid (42 students out of 85 students; 49\%) for teaching, which included; video lectures/demonstrations and webinars). Whereas, only $15 \%$ students favoured traditional white board teaching which was favoured only by 15 out of 100 students.

Similarly, majority (85\%) of the students agreed, that the teaching staff was punctual in delivering lectures and demonstrations. Although $80(80 \%)$ students were satisfied with the teaching in the labs and practical which included, demonstrations with audio visual aid (50 out of $80 ; 62 \%$ ) and conventional teaching 30(38\%). There was dissatisfaction about teaching in the OPDs and clinics, with satisfaction rates $40(40 \%)$ and $30(30 \%)$ respectively.

Regarding the method of assessments, 48(40\%) of students favoured short essay questions (SEQ's), 45(45\%) favoured multiple choice questions (MCQs), 15(15\%) favoured viva as an assessment tool respectively (Figure 2)

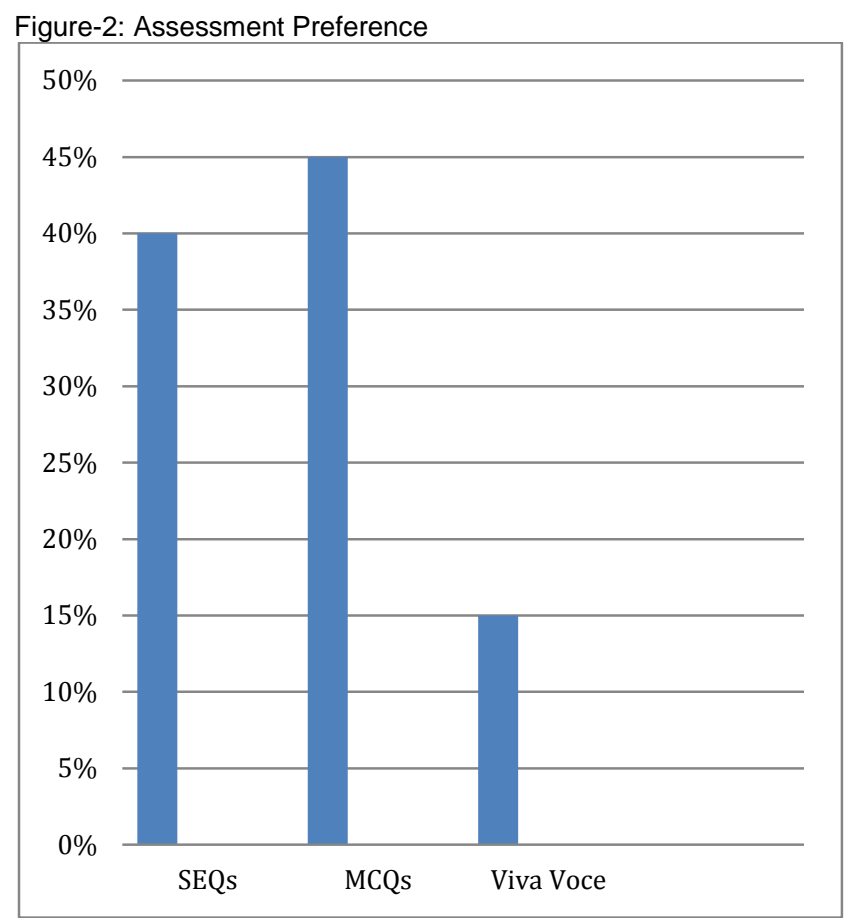

As far as the pattern of Objective Structured Clinical Examination (OSCE)/Objective Structured Practical Examination (OSPE) was concerned, 54(54\%) were of opinion, that the pattern of OSPE/OSCE is satisfactory. While, $46(456 \%)$ were dissatisfied with this form of assessment. Majority $100(61 \%)$ of the students felt that the time allowed for OSCE/OSPE was insufficient and the content assessed is elaborated.

As far as relevance of the questions is concerned, $57(57 \%)$ students answered in the agreement. Majority $100(74 \%)$ of the students agreed that multiple modes of assessment assisted in improvement of their knowledge and skill.

\section{DISCUSSION}

The ultimate objective of this survey is self-analysis of weaknesses and strengths in teaching methods. This current survey is significant. A significant percentage (73\%) of students were satisfied with various aspects of teaching being practiced including lectures, tutorial, small group discussions along with blended learning.70\% students favored blended learning as found in literature ${ }^{6}$ (Masood \& Aly 2014). Close results with $78 \%$ students favoring it has been shown by Rafique 1 .

In current study $85 \%$ students favoured multimedia power point presentations; whereas, $15 \%$ favoured traditional white board teaching. Study by Alhamdan also 
showed $79.4 \%$ of students favour power point lectures as the preferable method of lecturing ${ }^{8}$. Similar results have been expressed in other studies where majority of the students $79 \%{ }^{9}$ and $77.1 \%^{10}$ favoured multimedia as compared to old blackboard teaching ${ }^{9,10}$.

In present study $85 \%$ of students were satisfied with punctuality of teaching staff that is in accordance with another study at Nishter Medical College where $73 \%$ of students were satisfied ${ }^{1}$.

In this study $80 \%$ students showed satisfaction with dental labs teaching whereas dissatisfaction about teaching in the OPDs and dental clinics, which was quite strange. In another study $58 \%$ students were satisfied with teaching in ward, whereas bit dissatisfied with OPDs teaching with $30 \%$ satisfaction rates ${ }^{1}$.

This study demonstrated MCQs as a favourite tool of assessment followed by short essay questions and viva voce. Oyebola et $\mathrm{al}^{11}$ also showed students preference were MCQs based assessment that is in accordance with ours study. Another study ${ }^{9}$ revealed $62 \%$ student preferred MCQs for assessment followed by SEQs 37\%. A study conducted in Dayanand Medical College and hospital, Ludhiana, India, participants showed that assessment tools preferred by medical students were MCQs and short answer questions rather than long essay questions ${ }^{12}$.

An overwhelming response was observed regarding agreement on blended modes of learning and teaching i.e. assisting and enhancing psychomotor skill.Study conducted by Varthis $S$ also reported positive response of students as they perceived blended learning as a useful which demonstrate enhancement in social cognition and social constructivism learning ${ }^{13}$. A study at King Edward Medical Medical University, Lahore also demonstrated 50\% of student like blended form of learning for clearing complex concepts ${ }^{14}$.

\section{CONCLUSION}

In conclusion, the students undoubtedly are in the best position to Judge the effectiveness of teaching methods. Feedback has been called the life blood of learning and is thought to be particularly beneficial if provided under conditions that are stress free. Generally students were satisfied with the teaching method and blended learning techniques. Preferred method of assessment was considered to be MCQs and SEQs (short essay questions). Most of the students were satisfied with the OSPE Pattern being followed. There is a dire need to work on making of structured MCQs.

Limitation of study: This study has a few limitations. Study sample was small and may not represent the opinion of all the students of four years of BDS class thus results cannot be generalized. Close ended feedback gave limited access to the choices and expression of opinion openly. Students were asked to give the feedback individually but the presence of peers at the same time may have affected their opinion. Therefore a fraction of bias could not be ignored.

Conflict of interest: No conflict of interest regarding this study was reported.

Source of funding: Nil.

\section{REFERENCES}

1. Rafique S \& Rafique H., 2013. Student's feedback on teaching and assessment at Nishtar Medical College, Multan. J Pak Med Assoc., 63(9): 1205-1209

2. Vollmeyer R, Rheinberg F. A surprising effect of feedback on learning. Learning and Instruction. 2005 Dec 1;15(6):589-602.

3. Meenakshi S, Raghunath N, Shreeshyla HS. An assessment of teaching and learning practices: A questionnaire study for dental educators of Karnataka. Journal of International Society of Preventive \& Community Dentistry. 2017 Nov;7(Suppl 3):S179.

4. Urrutia-Aguilar ME, Guevara-Guzmán R, Sánchez-Mendiola M, Martínez-González A: Comprehensive assessment of teaching performance in medical education. Procedia Soc Behav Sci. 2014, 141:252-259. 10.1016/j.sbspro.2014.05.044

5. Shabbir A, Raja H, Qadri AA, Qadri MH. Faculty Feedback Program Evaluation in CIMS Multan, Pakistan. Cureus. 2020 Jun;12(6).

6. Jawaid M, Aly SM. 'E-learning'modalities in the current era of Medical Education in Pakistan. Pakistan journal of medical sciences. 2014 Sep;30(5):1156.

7. Rovai AP, Jordan H., 2004 Blended learning and sense of community: A comparative analysis with traditional and fully online graduate courses. Int Rev Res Open Dis; 5(2) Articles 5.2 .

8. AlHamdan EM, Tulbah HI, AIDuhayan GA, AIBedaiwi LS. Preferences of dental students towards teaching strategies in two major dental colleges in Riyadh, Saudi Arabia. Education Research International. 2016 Jan 1;2016

9. Hashmi NR, Daud S, Manzoor I: Medical Education: Views and Recommendations by Final Year MBBS Students of a Private Medical College in Lahore. J Coll Physicians Surg Pak 2010, 20(2):93-97.

10. Manzar B, Manzar N. To determine the level of satisfaction among medical students of a public sector medical university regarding their academic activities. BMC research notes. 2011 Dec;4(1):1-7.

11. Oyebola DD, Adewoye OE, lyaniwura JO, Alada AR, Fasanmade AA, Raji Y: A comparative study of students' performance in preclinical physiology assessed by multiple choice and SEQs. Afr J Med Sci 2000, 29:201-5.

12. Lata H, Walia L \& Gupta V., 2008. Student feedback on teaching and evaluation methodology in physiology. South East Asian Journal of Medical Education. 2(1): 31-37.

13. Varthis S, Anderson OR. Students' perceptions of a blended learning experience in dental education. European Journal of Dental Education. 2018 Feb;22(1):e35-41.

14. Naqvi SH, Mobasher F, Afzal MA, Umair M, Kohli AN, Bukhari $\mathrm{MH}$. Effectiveness of teaching methods in a medical institute: perceptions of medical students to teaching aids. J Pak Med Assoc. 2013 Jul 1;63(7):859-64. 